\title{
A comprehensive study of smoking in primary school children in Hong Kong: implications for prevention
}

\author{
Jean Peters, Anthony Johnson Hedley, Tai-Hing Lam, Carol Lane Betson, \\ Chit-Ming Wong
}

\begin{abstract}
Study objective-To identify factors associated with smoking behaviour in primary school children in Hong Kong.

Design-A cross sectional survey in which both children and parents completed questionnaires. The main outcome measure was the smoking status of the children; and risk factors (knowledge of and attitude to smoking and demographic and socioeconomic background) were identified as predictors of ever/never smoking.

Setting and subjects-Altogether 9598 primary school children, aged 8-13 years, and attending 27 schools from two districts in Hong Kong participated.

Main results-The prevalence of eversmoking was $12 \%(1119)-15 \%$ (760) in boys and $7 \%(359)$ in girls. It ranged from $3 \%$ in 8 year old girls to $52 \%$ in 13 year old boys. The factors associated with eversmoking included the following: being a boy (adjusted odds ratio 2.21 ; $95 \%$ confidence interval 1.89, 2.59), increasing age per year $(1.48 ; 1.40,1.57)$, living in Kwai Tsing district $(1.29 ; 1.10,1.50)$, having one or more smokers at home $(2.07 ; 1.78,2.39)$, and having a father who was not working $(1.41 ; 1.19,1.67)$. Children who were eversmokers had both seen and approved of their friends' smoking (8.79; 5.33, 14.50), had a more positive attitude towards smoking (3.35; 2.21, 5.09), and were more successful in recognising cigarette brand names and logos $(1.67 ; 1.42,1.96)$, but they lacked confidence $(1.78 ; 1.32,2.39)$.

Conclusions-The influences on child smoking are multifactorial and programmes in Hong Kong are failing to curb them. The control of these risk factors must be incorporated in the smoking prevention policy of Hong Kong and supported by future enforced legislation.
\end{abstract}

Department of

Community Medicine,

The University of Hong Kong, Patrick

Manson Building,

South Wing, 7 Sassoon

Road, Hong Kong

J Peters

A J Hedley

T-H Lam

C L Betson

C-M Wong

Correspondence to: Professor A J Hedley.

Accepted for publication September 1997
( $\mathcal{F}$ Epidemiol Community Health 1997;51:239-245)

The overall prevalence of smoking in the Hong Kong population is relatively low at $29 \%$ for men and $3 \%$ for women, ${ }^{1}$ but levels of smoking among young people, ${ }^{12}$ and young women in particular, ${ }^{3}$ are higher and increasing. Although the health risks of smoking, both active and passive, are well documented, ${ }^{45}$ and smoking is the single most preventable cause of death in Hong Kong, ${ }^{6}$ children do not seem to perceive future health risks as relevant to their current smoking behaviour.

With current targets ${ }^{7}$ to reduce smoking in children unlikely to be met in England, for example, this may be an appropriate time to re-examine the multiple factors associated with smoking in children. It has long been recognised in the west and more recently in South East Asia that the smoking behaviour of children is influenced or even condoned in some instances, by other family members, ${ }^{8-12}$ by friends, ${ }^{7-13}$ and by aggressive marketing activities of the transnational tobacco companies. ${ }^{13-18}$ The tobacco industry denies that its products are targeted at children, although in the Asia-Pacific rim marketing is aggressive, ${ }^{19}$ especially pitched at young people, and includes the cartoon image of Joe Camel which has been successfully identified as a cigarette logo by children as young as 3 years of age. ${ }^{20}$

Public health authorities have little information on the knowledge of health risks, and attitude towards and practices of smoking in Hong Kong primary school children. In studies of secondary school children the smoking prevalence varied from $18 \%-33 \% .^{122122}$ In the only previous study of primary school children, $8 \%$ declared they had smoking experience. ${ }^{23}$ This study aims to identify the social, demographic, and environmental factors among primary school children in Hong Kong that are associated with smoking experience and may contribute to the children's decision to become regular smokers. The applicability and acceptability of smoking prevention programmes in Hong Kong depends upon identifying these factors and then ensuring that they are addressed when smoking prevention policies are developed.

\section{Methods}

CHILDREN AND PARENTS

A four year study, commencing in 1989, was carried out to examine respiratory health and smoking behaviour in children attending primary classes three and four (aged 8-10 years) in 17 schools in two districts of Hong Kong. These districts were Kwai Tsing (a heavily industrialised and densely populated area) and Southern (predominantly residential). The original selection of districts was based on the differences in air quality. The principal criterion for selection of schools in Kwai Tsing was that they should be located in a subdistrict with poor air quality as rated by local officials and 
the Government Environmental Protection Department. In Southern district, because of its better air quality, all schools were situated in areas of low air pollution. The initial decision to recruit from classes primary three and four was based on the requirement for children whose lungs would be responsive to respiratory insult but who were also capable of filling in a questionnaire with little help and were less likely to have smoked. Details of the initial study design, the selection of schools and classes in 1989, and any sociodemographic differences between the two districts have been reported elsewhere. ${ }^{24-26}$ In the third year of the study, the original cohort, now in primary five and six (aged 11-13 years) were re-examined along with children currently in primary three and four. The study population was also extended with the recruitment of primary three and four children from an additional 10 schools situated in the same two districts and close to schools already participating in the study. This paper reports on the third year results.

\section{QUESTIONNAIRES}

Questionnaires written in Chinese were completed by both the children and their parents. Questions asking about the children's respiratory symptoms were taken and translated from internationally recognised standard questionnaires ${ }^{2728}$ and were repeated on both the parents' and children's questionnaires. In addition, the children's questionnaire included questions on smoking: their smoking practice; smoking by family members in the child's home; source of cigarettes; age at first smoking; and number of cigarettes smoked per day. Other questions examined knowledge of smoking and health; recognition of a selection of heavily advertised and popular brand names and logos, including tobacco brands, ${ }^{29}$ and the child's attitude to smoking.

The parents' questionnaire contained questions on: their own smoking history and current smoking status; smoking practice of others living in the family home; their opinion on children smoking; own educational attainment; housing type and size; current employment

\section{KEY POINTS}

- Recruitment of children to smoking is strongly associated with an environment in which the social acceptability of smoking is vigorously promoted.

- Tobacco advertising using images that young people find attractive is the most dominant factor overall.

- The tobacco industry is targeting children in Hong Kong and the Asia Pacific region and is funding campaigns to fight tobacco controls in both Hong Kong and mainland China.

- From a public health perspective enacting comprehensive legislation on advertising and sponsorship must be a priority for the new Special Administrative Region of Hong Kong. status; and occupation, given a list of options compiled from Hong Kong census guidelines. ${ }^{30}$

Parents' questionnaires were sent home and returned to the school in a sealed envelope. Children's questionnaires were completed in the classroom, supervised by trained research workers with no teachers present. The questionnaires were checked by the research team before leaving the school and any ambiguities or missing answers were followed up with the child concerned.

\section{ANALYSIS}

The child's smoking status was determined from a positive answer to one of six questions as follows: have never smoked; tried smoking a few times; used to smoke, but do not now; smoke sometimes, but less than 1 cigarette per week; smoke 1-6 cigarettes per week; smoke more than 6 cigarettes per week? A positive answer to the first question defined a child as a never-smoker. All those who answered any of the other five questions positively were considered ever-smokers.

Eight new summary variables were compiled as aggregates of answers to groups of variables, the individual variable answers being treated as binary responses and coded as 1 for "correct" or "yes" and 0 for all alternatives.

\section{Knowledge}

Responses to eight questions on knowledge related to smoking and health, eg "smoking makes it difficult for you to breathe" (table 3). Answer options were "true", "false", and "don't know".

\section{Attitude}

Responses to eight statements on smoking; eg "smoking is fun" (table 3). Answer options were "yes", "no", and "don't know".

\section{Confidence}

Responses to four questions on how confident children felt: in their school work, in sports, with friends, and in themselves. Answers were categorised from a five point scale into positive ("very confident", "confident" or "fairly confident") coded 0 and negative responses ("no" or "very poor confidence") coded 1 (table 3).

\section{Family smoking}

Responses to four questions relating to those who smoked and lived in the child's home, given as: mother, father, siblings, others. Responses were coded as the presence of "none", "one", or "two or more" of these smoker categories.

\section{Parental influence}

The sum of responses by the child (coded 1 for negative answers and 0 for positive) to the two questions "Would your mother (father) interfere if you smoked?" and dichotomised 
Table 1 Population studied and smoking status in relation to age and sex in Hong Kong children

\begin{tabular}{cccccc}
\hline & \multicolumn{2}{l}{ Population studied } & & \multicolumn{2}{l}{ Prevalence of ever-smokers } \\
\cline { 2 - 3 } \cline { 5 - 6 } & Boys & Girls & & Boys & Girls \\
\cline { 2 - 3 } \cline { 5 - 6 } Age $(y)$ & No (\%) & No (\%) & & No (\%) & No (\%) \\
\hline 8 & $810(16)$ & $825(18)$ & & $59(7)$ & $28(3)$ \\
9 & $1325(27)$ & $1414(30)$ & & $115(9)$ & $71(5)$ \\
10 & $1140(23)$ & $1129(24)$ & & $158(14)$ & $67(6)$ \\
11 & $976(20)$ & $800(17)$ & & $202(21)$ & $73(9)$ \\
12 & $524(11)$ & $417(9)$ & & $148(28)$ & $52(13)$ \\
$\geq 13$ & $150(3)$ & $88(2)$ & & $78(52)$ & $18(20)$ \\
Total & $4925(100)$ & $4672(100)$ & & $760(15)$ & $359(7)$ \\
\hline
\end{tabular}

into 1 (two negative responses) compared with 0 (one or no negative responses).

\section{Teacher influence}

The sum of responses to the questions; "Do you think a teacher would interfere if you smoked?" (negative responses coded as 1 , positive as 0 ) and; "Have you seen a teacher smoke?", "Do you consider it acceptable for a teacher to smoke?" (positive responses coded as 1 , negative as 0 ). Answers were dichotomised into 1 (for a response total of 3 ) and 0 (for all other total response options).

\section{Peer influence}

The sum of responses (positive coded as 1 , negative as 0 ) to the two questions; "Have you seen your classmates smoke?" and "Do you consider it acceptable for your classmates to smoke?" with the total dichotomised into 1 (two positive answers) and 0 (one or no positive answers).

\section{Brand recognition}

Successful recognition of 13 brand names and logos as one of four categories, given the following five options for answers: "food", "drink", "cigarettes", "other", and "don't know". The brand names and logos included in the questionnaire were as follows:

- Food: McDonald's (logo), Cadbury (name), Garden bakery (logo),

- Drink: Carlsberg (logo and name), Martell (name), Coca Cola (logo),

- Cigarettes: Salem (logo and name), Marlboro (logo and name),

- Other. Colgate (logo and name). ${ }^{29}$

All analyses were carried out using SPSS/ PC4.0. The completion rate for all questions on the children's questionnaire was $99 \%$ or higher with the exception of the question relating to the recognition of the McDonald's logo. This question caused confusion in the children as it could be answered in three of the five categories and $5 \%$ gave no answer. Responses with missing data were excluded from relevant scores.

Crude prevalence ratios and $95 \%$ confidence intervals (CI) were calculated. Differences were examined between the children who were never and ever-smokers for demographic, social, and environmental factors and smoking behaviour using $t$ tests and $\chi^{2}$ tests as applicable. The association between potential independent factors and child smoking was examined by calculating the odds ratios (OR) with $95 \% \mathrm{CI}$. The scores from the eight computed variables were examined for association with smoking behaviour by inclusion in a logistic regression model together with age, sex, attained parental education level (no formal education compared with primary, lower, upper or post secondary), parental occupational status (not in work compared with working), housing type (public housing compared with all other) and district of residence (Kwai Tsing compared with Southern). The adjusted OR ( $95 \%$ CI) were determined for all these factors. The final logistic regression model included all variables significant at $\mathrm{p}<0.05$.

\section{Results}

\section{RESPONSE RATE AND DEMOGRAPHY}

Responses from schools (100\%) and parents (96\%) were good. A total of 9657 children completed questionnaires-over $98 \%$ of the total study population. There were no refusals and the only questionnaires missing were from the 119 children absent from school on the day of the fieldwork. The final data set consisted of 9598 children who answered the question on their smoking status (table 1).

There were no differences between the two districts in gender mix $\left(\chi^{2}=1.27, \mathrm{p}=0.26\right)$ or age $(t=-1.22, \mathrm{p}=0.22)$. The children living in Southern district had a mean age of 10.3 years $(95 \%$ CI 10.3, 10.4), and those in Kwai Tsing had a mean age of 10.4 years (10.3, $10.4)$. Boys (10.4 (10.4, 10.5) years) were slightly older than the girls (10.3 years (10.2, 10.3) $(\mathrm{t}=-5.99, \mathrm{p}<0.001))$.

\section{SMOKING PRACTICE}

Twelve per cent (1119) of the children-15\% boys (760) and $7 \%$ girls (359) - declared they had smoking experience. Ever-smokers were on average older (mean age $11.1(11.0,11.2)$ years) than never smokers $(10.2(10.2,10.3)$ years $)(t=-20.64, \mathrm{p}<0.001)$. Boys who smoked were older (mean age $11.2(11.1,11.3)$ years) than smoking girls $(10.9(10.7,11.0)$ years) $(t=3.22, \mathrm{p}<0.001)$ and smoking prevalence increased with age (table 1 ).

Ever-smokers started smoking, on average, at $7.8(7.6,7.9)$ years, with no differences between girls and boys $(t=0.26, \mathrm{p}=0.79)$ and overall they had smoked $0.5(0.4,0.6)$ cigarettes in the last 24 hours. For those 230 children who claimed to have smoked at least one cigarette since yesterday, the mean number smoked was $2.1(1.8,2.5)$, with no differences between girls and boys.

The ever-smoking children bought their cigarettes from a number of outlets, mainly shops (table 2). There were no differences by sex for place of purchase with the exception of supermarkets (OR $=1.61 ; 95 \%$ CI $1.17,2.20)$. Other than purchase, these children obtained cigarettes from friends and family, with fathers being the biggest providers (table 2 ). 
Table 2 Source of cigarettes for ever-smokers

\begin{tabular}{llll}
\hline & $\begin{array}{l}\text { Boys } \\
(n=759) \\
\%\end{array}$ & $\begin{array}{l}\text { Girls } \\
(n=308) \\
\%\end{array}$ & $\begin{array}{l}\text { Total } \\
(n=1067) \\
\%\end{array}$ \\
Source & & & \\
\hline Purchased from: & 44 & 45 & 44 \\
$\quad$ Shóps & 30 & 21 & 27 \\
Supermarkets & 26 & 22 & 25 \\
Stalls & 27 & 23 & 25 \\
$\quad$ Others & 3 & 6 & 4 \\
Acquired from: & 19 & 24 & 21 \\
$\quad$ Mother & 6 & 8 & 7 \\
Father & 0 & 0 & 0 \\
Elder siblings & 9 & 12 & 10 \\
Younger siblings & 17 & 19 & 17 \\
Grandparents & 12 & 9 & 11 \\
$\quad$ Relatives & 18 & 13 & 17 \\
Classmates & 15 & 11 & 14 \\
$\quad$ Friends & & & \\
Others & &
\end{tabular}

Note: percentages do not add up to $100 \%$ as more than one answer may be given.

KNOWLEDGE, ATTITUDE, AND CONFIDENCE

Nine per cent (796) answered all eight knowledge questions correctly. The mean score was $5.5(5.4,5.5)$ with no differences between the ever and never-smoking children $(t=-0.32$, $\mathrm{p}=0.75$ ). Responses to individual knowledge and attitude questions in relation to child smoking status are given in table 3 and show eversmokers as having a more positive attitude towards smoking with the exception of "Smoking is a waste of money".

Ever-smokers had less confidence than never-smokers in their schoolwork, with friends, and in themselves but there were no differences for sport (table 3).

Differences in the children's level of knowledge of the health risks of smoking, attitude towards smoking, and lack of confidence in relation to age and sex are shown in table 4 . Significant improvements in knowledge occur with increasing age in both sexes and there are considerable differences between boys and girls, with the boys having the better knowledge in every case except for smoking causing dandruff, where the girls were better informed. In general, the overall level of knowledge was good

Table 3 Knowledge of health risks, attitude to smoking, and confidence in relation to the smoking status of the child

\begin{tabular}{|c|c|c|c|c|}
\hline Question & $\begin{array}{l}\text { Ever-smoker } \\
(n=1056- \\
1065) \\
\%\end{array}$ & $\begin{array}{l}\text { Never-smoker } \\
(n=8470- \\
8517) \\
\%\end{array}$ & OR $(95 \% C I)$ & $p$ \\
\hline \multicolumn{5}{|c|}{ Knowledge: \% answering correctly } \\
\hline Breathing difficulties & 64 & 69 & $0.80(0.70,0.92)$ & 0.001 \\
\hline Coughing & 76 & 77 & $0.96(0.83,1.12)$ & 0.64 \\
\hline Dandruff & 64 & 66 & $0.92(0.80 .1 .05)$ & 0.15 \\
\hline Lung problems & 92 & 89 & $1.40(1.11,1.76)$ & 0.004 \\
\hline Heart problems & 58 & 57 & $1.05(0.92,1.19)$ & 0.49 \\
\hline Cancers & 82 & 80 & $1.17(0.99,1.38)$ & 0.08 \\
\hline Colds & 29 & 28 & $1.02(0.88,1.18)$ & 0.82 \\
\hline Addiction & 83 & 81 & $1.08(0.92,1.28)$ & 0.38 \\
\hline \multicolumn{5}{|l|}{ Attitude: $\%$ answering yes } \\
\hline $\begin{array}{l}\text { Smoking: } \\
\text { Is fun }\end{array}$ & 6 & 2 & $4.23(3.11,5.76)$ & $<0.001$ \\
\hline Calms your nerves & 14 & 8 & $2.19(1.83,2.62)$ & $<0.001$ \\
\hline Makes you look tough & 7 & 4 & $1.95(1.49,2.53)$ & $<0.001$ \\
\hline Is a waste of money & 86 & 86 & $1.02(0.85,1.22)$ & 0.90 \\
\hline Makes you feel mature & 8 & 3 & $2.41(1.88,3.10)$ & $<0.001$ \\
\hline Gives you confidence & 5 & 2 & $2.53(1.81,3.52)$ & $<0.001$ \\
\hline Is for showing off & 17 & 8 & $2.55(1.83,3.55)$ & $<0.001$ \\
\hline Makes you lose weight & 4 & 2 & $2.49(1.79,3.47)$ & $<0.001$ \\
\hline \multicolumn{5}{|l|}{ Confidence: \% answering no } \\
\hline $\begin{array}{l}\text { Have confidence: } \\
\text { In schoolwork }\end{array}$ & 13 & 6 & $2.45(2.01,2.99)$ & $<0.001$ \\
\hline In sports & 7 & 6 & $1.16(0.91,1.49)$ & 0.27 \\
\hline With friends & 6 & 4 & $1.60(1.22,2.11)$ & $<0.001$ \\
\hline In self & 9 & 4 & 2.27 (1.78. 2.88) & $<0.001$ \\
\hline
\end{tabular}

and the children were well aware of health risks such as smoking causes lung problems and cancer. In contrast, for attitude, there were fewer differences across the age groups. There was increased agreement with the view that smoking is "for showing off" and "a waste of money", and for the girls only, with increasing age, reduced numbers were of the opinion that smoking makes you "look tough", "feel grownup" and "gives you confidence". For every statistically significant difference in response between the sexes in the attitude questions, a higher proportion of boys gave the answer "yes". Lack of confidence in schoolwork, sport, and with friends increased with age for the girls but not for the boys. Overall boys were less confident in their schoolwork and girls in sport.

\section{SOCIAL AND ENVIRONMENTAL FACTORS}

About $40 \%$ of the children, both the ever and never-smokers, lived in public housing with $55 \%$ (584) of the ever-smoking children living in Kwai Tsing and 45\% (484) in Southern district.

The ever-smoking children tended to have mothers who were out of the house at work, but whose fathers were unemployed (table 5). There were also differences in the type of job done with a higher proportion of mothers of the ever-smoking children working in manufacturing and sales and fewer in professional and clerical jobs $\left(\chi^{2}=35.9, p<0.001\right)$. For fathers, although there were differences in relation to occupation $\left(\chi^{2}=12.7, \mathrm{p}<0.05\right)$, the pattern was less clear cut.

Eighteen per cent of the ever-smoking children compared with $14 \%$ of the never-smokers had mothers who had received no formal education (table 5).

Thirty three per cent (3164) of the children lived in a family with one smoker category and $10 \%$ (922) with two or more. There were strong associations between the children's smoking experience and smoking by other household members: mother $(\mathrm{OR}=3.26 ; 95 \%$ CI 2.49 , 4.26); father $(1.70 ; 1.49,1.93)$; siblings (4.92; $4.05,5.98)$; others $(1.53 ; 1.29,1.82)$.

One per cent (79) of parents had no objection to their child smoking-this proportion was $3 \%$ in the smoking and $0.7 \%$ in the nonsmoking parents $(\mathrm{OR}=3.86 ; 95 \%$ CI 2.43 , $6.12)$. The ever-smoking children were more likely to believe that neither their parents or their teachers would interfere if they smoked and to have seen both their classmates and teachers smoke, and consider it acceptable for them to do so (table 5).

Differences related to the children's age and sex in these opinions reflect the different patterns of smoking seen in the two sexes. A higher proportion of boys claimed that their parents would not interfere if they smoked, that they had both seen their classmates and teachers smoke, and considered it acceptable for them to do so. Both sexes showed significant changes in opinion with age, with the exception of the girls' opinion that their parents would not interfere if they smoked (table 4). 
Table 4 Percentage response to questions on knowledge, attitude, opinion, and confidence in relation to age and sex

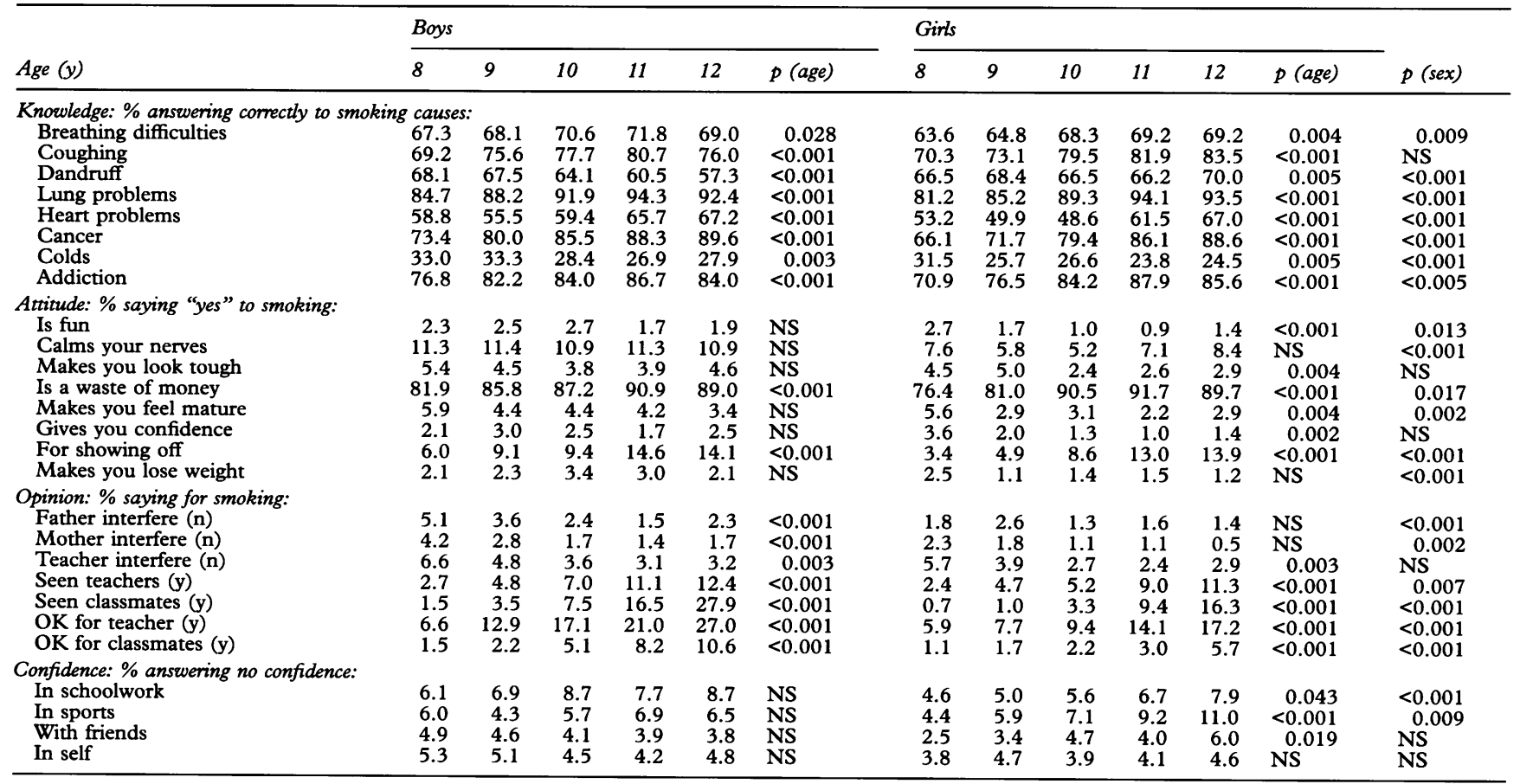

Note: children aged 13 and over excluded from the table because of small subject numbers but not from the statistical analysis; $(\mathrm{n})=$ no, $(\mathrm{y})=$ yes, ns $=$ not significant $=\mathrm{p}>0.05$

Table 5 Factors associated with smoking behaviour

\begin{tabular}{|c|c|c|c|c|c|}
\hline Factor & & $\begin{array}{l}\text { Ever-smoker } \\
(n=1022-1068) \\
\%\end{array}$ & $\begin{array}{l}\text { Never-smoker } \\
(n=8021-8530) \\
\%\end{array}$ & $\begin{array}{l}\text { Crude OR } \\
(95 \% \text { CI) }\end{array}$ & $\begin{array}{l}\text { Adjusted OR } \\
(95 \% \text { CI) }\end{array}$ \\
\hline \multirow{7}{*}{$\begin{array}{l}\text { Sex } \\
\text { Age } \\
\text { Knowledge } \\
\text { Correct attitude } \\
\text { Confidence } \\
\text { District } \\
\text { Housing } \\
\text { No employment }\end{array}$} & \multirow{6}{*}{$\begin{array}{l}\text { Being a boy } \\
\text { Per year } \\
\geq 50 \% \\
\geq 50 \% \text { yes } \\
>50 \% \text { say no } \\
\text { Kwai Tsing } \\
\text { Public }\end{array}$} & 71 & 49 & $2.58(2.25,2.97)$ & \multirow[t]{2}{*}{$\begin{array}{l}2.21(1.89,2.59) \\
1.48(1.40,1.57)\end{array}$} \\
\hline & & 76 & 76 & $1.00(0.86,1.16)$ & \\
\hline & & 3 & 0.4 & $7.05(4.31,11.5)$ & \multirow{4}{*}{$\begin{array}{l}3.35(2.21,5.09) \\
1.78(1.32,2.39) \\
1.29(1.10,1.50)\end{array}$} \\
\hline & & 25 & 14 & $2.03(1.74,2.37)$ & \\
\hline & & $\begin{array}{l}55 \\
39\end{array}$ & $\begin{array}{l}48 \\
38\end{array}$ & $1.31(1.15,1.49)$ & \\
\hline & & & & $0.90(0.84,1.10)$ & \\
\hline & Mother & 50 & 57 & $0.85(0.73,0.98)$ & \multirow{3}{*}{$1.41(1.19,1.67)$} \\
\hline \multirow{2}{*}{ No formal education } & Father & 13 & 8 & $1.64(1.25,2.14)$ & \\
\hline & Mother & $\begin{array}{l}18 \\
10\end{array}$ & $\begin{array}{r}14 \\
9\end{array}$ & $1.27(1.06,1.52)$ & \\
\hline \multirow{7}{*}{$\begin{array}{l}\text { Family smoking } \\
\text { Parental } \\
\text { Teacher } \\
\text { Peer } \\
\text { Brand }\end{array}$} & $\begin{array}{l}\text { Father } \\
\geq 1 \text { smokers }\end{array}$ & $\begin{array}{l}10 \\
60\end{array}$ & $\begin{array}{r}9 \\
40\end{array}$ & $\begin{array}{l}1.13(0.90,1.41) \\
2.26(198,258)\end{array}$ & \multirow{3}{*}{$2.07(1.78,2.39)$} \\
\hline & + ve influence & 20 & 15 & $\begin{array}{l}2.26(1.98,2.58) \\
1.37(1.16,1.61)\end{array}$ & \\
\hline & +ve influence & 60 & 46 & $1.71(1.50,1.94)$ & \\
\hline & $\begin{array}{l}\text { +ve influence } \\
100 \% \text { correct }\end{array}$ & 31 & 7 & $5.80(4.98,6.77)$ & $8.79(5.33,14.50)$ \\
\hline & $\begin{array}{l}\text { Food } \\
\text { Drink }\end{array}$ & $\begin{array}{l}72 \\
63\end{array}$ & $\begin{array}{l}73 \\
57\end{array}$ & $\begin{array}{l}0.94(0.81,1.08) \\
1.31(1.15,1.50)\end{array}$ & \multirow{3}{*}{$1.67(1.42,1.96)$} \\
\hline & Cigarettes & 64 & 41 & $2.48(2.17,2.83)$ & \\
\hline & Toothpaste & 71 & 67 & $1.23(1.07,1.42)$ & \\
\hline
\end{tabular}

BRAND RECOGNITION

The ever-smoking children were more successful in recognising cigarette brand names and logos than the never-smokers (table 5). Twenty eight per cent of 8 year old children recognised all four tobacco-related names and logos correctly, and success increased with age to $72 \%$ in 13 year olds. Out of all the 13 brand names and logos given, the two most successfully identified (both $95 \%$ correct) were the Salem logo and Marlboro name.

\section{ESTIMATED ADJUSTED ODDS RATIOS}

Logistic regression analysis resulted in nine factors remaining as significant predictors of smoking behaviour with correct prediction of $89 \%$ of these children as ever or never-smokers. Compared with the never-smokers, the ever- smokers tended to be boys and to live in a smoking family. They had, and approved of, friends who smoked, had a positive attitude to smoking, and could recognise cigarette brands more successfully, although they were equally successful at recognising other brands. These ever-smokers, although more likely to be older, had less confidence, lived in the mixed industrial residential urban area of Kwai Tsing, and had a father currently unemployed. The adjusted OR and $95 \% \mathrm{CI}$ for these nine risk factors are given in table 5 . In terms of the relative importance of the background factors, likelihood ratio tests for each variable included and not included in the logistic model showed that district $\left(\chi^{2}=12.18, \mathrm{df}=1, \mathrm{p}<0.001\right)$, father not working $\left(\chi^{2}=16.29, \mathrm{df}=1, \mathrm{p}<0.001\right)$ and to lesser extent, mother working $\left(\chi^{2}=3.97\right.$, $\mathrm{df}=1, \mathrm{p}<0.05$ ) made a significant impact on 
the prediction of a child as an ever-smoker but parental education and housing seemed less important and were non-significant $(p>0.05)$.

\section{Discussion}

Factors associated with childhood experimentation with smoking, although well documented in the west have not been fully explored in Hong Kong and other areas of the Asia Pacific region. This study, the first in Hong Kong to model such a comprehensive range of potentially influencing factors, indicates that Hong Kong children are experimenting with smoking from a very early age. By the age of 12 , one in five has tried smoking, and a clear increasing trend in ever-smoking prevalence is evident in Hong Kong primary school children aged 8 through to secondary school children aged $15 .^{12122}$

Although these responses have not been validated with cotinine studies, validity can be inferred from the consistency found in the estimated excess risks in child smokers, of cough, wheeze, and phlegm over the four years of this study, ${ }^{24-26}$ and the high level of agreement between parental and children's responses on questions relating to smoking practice. Personal reporting of smoking behaviour has also been shown to be reliable. ${ }^{31}$

While socioeconomic factors, measured by housing type, education and occupation, appear to have less of an influence in Hong Kong than in other countries ${ }^{91032}$ these ever-smoking children were more likely to have an unemployed father in a territory where, at the time of the survey, employment was higher than $98 \% .{ }^{33}$ Family influence remains important in Hong Kong ${ }^{12}$ as in other countries. ${ }^{8-1013}$ These children were found to be twice as likely to smoke if they lived in a home where one or more members of the family household smoked and, in some instances, family members were prepared to provide them with the cigarettes. Fathers gave cigarettes to one fifth of the child smokers in this study. Outside of the family, peer pressure was found to be a major influential factor in this study as elsewhere. ${ }^{8-14}$ Evidence of an influential role by teachers is limited, ${ }^{34}$ and we found no association between the child's opinions of their teachers smoking and their own practice after adjustment for other influential factors. However, as role models with credibility from a child's viewpoint, parents and teachers both have an opportunity to influence acceptance of the "no smoking" message by not smoking themselves. Such action would not only provide a healthy role model but also lead to a reduction in passive smoking, a health hazard in its own right ${ }^{5}$ and a greater risk for children's respiratory problems in the Territory than ambient air pollution. ${ }^{24-26}$ It is essential that initiatives to tackle child smoking include promotion of negative attitudes to smoking in adults.

The ever-smoking children in this study, as elsewhere, ${ }^{810}$ believe that smoking is fun and makes you look grown up, images which some children perceive as portrayed by cigarette advertisements. ${ }^{15}$ Even though ever-smoking chil- dren are more successful in identifying advertised tobacco brand names and logos, non-smokers are not unsuccessful. ${ }^{2935}$ In Hong Kong the tobacco industry continues to use advertisements targeted at children ${ }^{1720}$ and sponsorship of sports and cultural events regarded as exciting and glamorous by young children; this is a major obstacle for smoking prevention programmes to overcome. Despite a partial ban on tobacco advertising, children's exposure to tobacco advertisements in Hong Kong, as elsewhere, is not prevented nor is their subsequent ability to recall them limited. ${ }^{2036} \mathrm{~A}$ total ban on advertising is needed, including sponsorship by the tobacco industry of cultural and sporting events. There is evidence that such bans can work, ${ }^{37}$ and Hong Kong residents, including smokers, have consistently expressed support for such bans over the last seven years. ${ }^{38-40}$ Fiscal measures, such as hypothecated taxes, which have been successfully implemented in Australia, ${ }^{41}$ are unlikely to directly dissuade children from smoking. But the use of such revenue, not only to fund health care services and health promotion but also sponsorship of sports and cultural events, at least removes the tobacco industry's advertising impact from such events. Legislation introduced since this survey was completed has banned sales of tobacco products to those below 18 years but rigorous enforcement will be necessary as children in this study aged 8-12 years were able to purchase cigarettes.

Changing intentions to smoke needs to start in the classroom with specifically trained teachers and a spiral curriculum suitably structured to cater for the significant development seen in children's knowledge, attitude, opinions, and confidence with increasing age and the wide diversity occurring in some instances between the sexes, as demonstrated in this study. Education programmes need to focus on encouraging a sense of internal control in the children, rather than external prohibition, as this is more effective in helping children to resist temptations. Improving knowledge levels alone is not enough as we found these to be reasonable in both our never and ever-smoking children. Programmes need to include "inoculation" against tobacco advertising, the boosting of self confidence, and development of refusal skills for children to resist the influence and pressure, real or apparent, of peers and family. Resistance to temptation to smoke can be increased in children by labelling them as "able" in resisting temptation, ${ }^{42}$ thereby contributing to their greater sense of self efficacy. ${ }^{43}$ Evidence shows that smokers rate smoking benefits as greater, and costs as less, than nonsmokers. ${ }^{44}$ The intention to smoke is, therefore, amongst other things, a function of the person's positive or negative evaluation of smoking and their perception of whether any referents, such as peers (as is demonstrated very clearly in this study), approve or disapprove of smoking. ${ }^{44}$ So anti-smoking education programmes need to focus on attitudes towards smoking. More particularly, concentrating on increasing the children's sense of their own effectiveness, both in being socially effective without cigarettes and 
in resisting temptation to adopt indulgent behaviours generally, and towards tobacco, specifically. Tobacco advertising can increase social discontent among young people by generating or strengthening desires for promoted products, ${ }^{43}$ so sustained media campaigns to deglamourise smoking behaviour need to be run in tandem with anti-smoking promotions in schools and elsewhere. Such programmes must begin at primary school level as children with a smoking history by 9 years of age are more likely to still be smokers at $13 .{ }^{46}$

The problem is not unique to Hong Kong and the Hong Kong Government needs to learn from the efforts of other countries. It needs to set targets, as in other countries ${ }^{7}$ for a reduction in smoking prevalence with special attention to specific high risk groups, such as children. In conjunction with this it needs to provide an adequately resourced united approach through legislation, education, ongoing monitoring, and evaluation. This study indicates that smoking is a paediatric problem in Hong Kong and that in primary school children it is associated with marked respiratory ill health effects. ${ }^{24-26}$ There is a need to act now if we wish to reduce, or even contain, the predicted levels of mortality and morbidity from tobacco related diseases into the next century. ${ }^{4}$

We thank Dr R Fielding for his helpful comments and advice on health education, all the schools, teachers, parents, and children who took part in this study, and members of the research team.

Funding: the authors gratefully acknowledge financial support from the Environmental Protection Department, Hong Kong Government, the Hong Kong Jockey Club (Charities) Ltd, Kwai Tsing District Board, Glaxo Hong Kong Ltd, the MarySun Medical Scholarship Fund (Hong Kong-Cambridge Link), and the University of Hong Kong Conference and Research Grants Committee.

Conflicts of interest: none.

1 Census and Statistics Department, Hong Kong Government. Special topics report VII. General household survey 1990. Hong Kong: Government Printer 1991.

2 Census and Statistics Department, Hong Kong Government. Special topics report I. General household survey 1982. Hong Kong: Government Printer 1983.

3 Li C, Fielding R, Marcoolyn G, Wong CM, Hedley AJ. Health beliefs, expectations and perceived benefits of smoking in Asian women. Tobacco Control 1994:3:21-9.

4 Peto R, Lopez AD, Boreham J, Thun M, Heath C. Mortality from smoking in developed countries 1950-2000. Oxford: Oxford University Press 1994:553.

5 Environmental Protection Agency. Respiratory health effects of passive smoking: lung cancer and other disorders. EPA/600/ 6-90/006F Washington DC: EPA, 1992:1-1.

6 Department of Health, Hong Kong. Public health report no 1. A new approach to the public health report. Coronary heart disease and lung cancer. Hong Kong: Government Printer 1994:52.

7 Secretary of State for Health. The health of the nation: a strategy for health in England. Cm 1986. London: HMSO 1992.

8 Bewley BR, Bland JM, Harris R. Factors associated with the starting of cigarette smoking by primary school children. $\mathrm{Br}$ F Prev Soc Med 1974;28:37-44.

9 O'Connell DL, Alexander HM, Dobson AJ, et al. Cigarette smoking and drug use in schoolchildren. II Factors associated with smoking. Int $\mathcal{f}$ Epidemiol 1981;10:223-31.

10 Murray M, Swan AV, Johnson RD, Bewley BR. Some factors associated with increased risk of smoking by children. $f$ Child Psychol Psychiatry 1983;24:223-32.

11 Chung J, Mackay J, Munro C, Tse MR. Smoking in Chinese secondary school children in Hong Kong II Attitudes and knowledge. Hong Kong Practitioner 1989;11:159-69.

12 Hertz AZ. Smoking among junior secondary school children in Hong Kong in 1990. A report to The Hong Kong Council on Smoking and Health. Hong Kong: Hong Kong Council on Smoking and Health, 1990:1-22.

13 Armstrong BK, de Klerk NH, Shean RE, Dunn DA, Dolin PJ. Influence of education and advertising on the uptake of smoking by children. Med $\mathcal{F}$ Aust 1990;152:117-24.
14 Botvin GJ, Goldberg CJ, Botvin EM, Dusenbury L. Smoking behaviour of adolescents exposed to cigarette advertising. Public Health Rep 1993;108:217-24.

15 Potts H, Gillies P, Herbert M. Adolescent smoking and opinion of cigarette advertisements. Health Education Research 1986;1:195-201

16 Pierce JP, Gilpin E, Burns DM, et al. Does tobacco advertising target young people to start smoking? Evidence from California. $\mathcal{F A M A}$ 1991;266:3154-8.

17 Di Franza JR, Richards JW, Paulman PM, et al. RJR Nabisco's cartoon camel promotes Camel cigarettes to children. FAMA 1991;266:3149-53.

18 Pierce J, Lee L, Gilpin EA. Smoking initiation by adolescent girls, 1944 through 1988 . An association with targeted girls, 1944 through 1988. An associati
advertising. $¥ A M A 1994 ; 271: 608-11$.

19 Mackay JL. The fight against tobacco in developing countries. Tuber Lung Dis 1994;75:8-24.

20 Fischer PM, Schwartz MP, Richards JW, Goldstein AO, Rojas TH. Brand logo recognition by children aged 3 to 6 years. $\mathcal{F} A M A \quad 1991 ; 266: 3145-8$.

21 Chung J, Mackay J, Munro C, Tse M. Smoking in Chinese secondary school children in Hong Kong I Prevalence. Hong Kong Practitioner 1989;11:91-99.

22 Lam TH, Chung SF, Wong CM, Hedley AJ, Betson CL Youth smoking, health and tobacco promotion. The Youth Smoking and Health Survey. Hong Kong: Council on Smoking and Health. 1994:6.

23 Peters J, Hedley AJ, Lam TH, Liu J, Wong CM, Ong SG Factors influencing smoking behaviour in Hong Kong primary schoolchildren: targets for prevention. Asia Pacific foumal of Public Health 1995;8:102-8.

24 Ong SG, Liu J, Wong CM, et al. Studies on the respiratory health of primary school children in urban communities of Hong Kong. The Science of the Total Environment 1991; of Hong Kong.

25 Hedley AJ, Peters J, Lam TH, et al. Air pollution and respiratory health in primary school children, 1989-1992. Report to the Environmental Protection Department, Hong Kong Government. Hong Kong: Department of Community Medicine, The University of Hong Kong. 1993:311.

26 Peters J, Hedley AJ, Wong CM, Lam TH, Ong SG, Liu J, Spiegelhalter DJ. Effects of an ambient air pollution intervention and environmental tobacco smoke on children's respiratory health in Hong Kong. Int $\mathcal{f}$ Epidemiol. 1996;25:821-28.

27 Medical Research Council. Questionnaire on respiratory symptoms, 1960. London: MRC.

28 Florey C du V, Leeder SR. Methods for cohort studies of chronic aifflow limitation. Copenhagen:WHO, 1982. WHO Regional Publications, European Series No 12

29 Peters J, Betson CL, Hedley AJ, et al. Recognition of cigarette brand names and logos in young children in Hong Kong. Tobacco Control 1995;4:150-5

30 Hong Kong 1991 population census. Hong Kong: Government Printer, 1991.

31 Barnea Z, Rahav G, Teichman $M$. The reliability and consistency of self-reports on substance use in a longitudinal study. $B r \mathcal{F}$ Addiction 1987;82:891-98.

32 Bellew B, Wayne D. Prevention of smoking among schoolchildren: a review of research and recommendations. Health Educ f 1991;50:3-8.

33 Hong Kong 1993. A review of 1992. Hong Kong: Government Printer, 1993:97.

34 Bewley BR, Johnson MRD, Banks MH. Teachers' smoking. Y Epidemiol Community Health 1979;33:219-22.

35 Ch. .ritton A. Children's advertisement-awareness related to thir views on smoking. Health Educ $\mathcal{F} 1986 ; 45: 75-8$.

36 Nelso. $E$, Charlton A. Children and advertising: does the Volu.

37 Smee $($. Effect of tobacco advertising on tobacco consumption: a discursion document reviewing the evidence. London: Economics and Operational Research Division, Department of Heatch, 1992

38 Lam TH, Donnan SPB, Cheng KK, Chan NF. A public opinion survey on proposed legislative changes on smoking control. In: Durstan B, Jamrozik K. eds. Tobacco and health 1990 the global war. Proceedings of the Seventh World Conference on Tobacco and Health, 1990:726-28.

39 Cheng KK, Hedley AJ, Bacon-Shone J, Lam TH, Peters J, Chan A. A Public opinion survey on measures related to the control of smoking in Hong Kong. Hong Kong: Department of Community Medicine and Social Sciences Research Centre, The University of Hong Kong. 1993:12.

40 Lam TH, Chung SF, Hedley AJ, Sum SM. Public opinion on banning of tobacco advertisements and sponsorship 1995.

41 Vic Health Annual Report 1994. Victoria, NSW: Victoria Health Promotion Foundation, 1994:92.

42 Miller RL, Brickman P, Bolen D. Attribution versus persuasion as a means for modifying behaviour. $\mathcal{F}$ Pers Soc Psychol 1975;31:43

43 Bandura A. Social foundations of thought and action: a social cognitive theory. New Jersey: Prentice Hall Inc; 1986

$44 \mathrm{Li} \mathrm{C}$, Fielding R, Hedley AJ. Survey of knowledge, perceptions and behaviour related to smoking in young Asian women airline cabin crew. Health Educ $\mathcal{F}$ 1996;55:92-100.

45 Ajzen I. Attitudes, personality and behaviour. Milton Keynes: OUP, 1988.

46 McGee R, Stanton WR. A longitudinal study of reasons for smoking in adolescence. Addiction 1993;88:265-71. 